\title{
IDENTIFICAÇÃO DE QTLS EM FEIJOEIRO POR MEIO DE MARCADORES SSR INFLUENCIADOS PELA SELEÇÃO NATURAL
}

\author{
QTLs identification in common bean through SSR markers affected by natural selection
}

\author{
Taislene Butarello Rodrigues ${ }^{1}$, João Bosco dos Santos², Magno Antonio Patto Ramalho ${ }^{3}$, \\ Edson Perito Amorim ${ }^{4}$, Nara Oliveira Silva ${ }^{5}$
}

\begin{abstract}
RESUMO
Para identificar QTLs para produtividade de grãos e peso de 100 sementes em feijoeiro (Phaseolus vulgaris L.), foram usados microssatélites influenciados pela seleção natural, identificados na população derivada do cruzamento 'Carioca MG' $\mathrm{x}$ 'ESAL 686', conduzida pelo método da população até a geração $\mathrm{F}_{24}$. Foram avaliadas 107 linhagens da geração $\mathrm{F}_{8}$ e 107 da $\mathrm{F}_{24}$ em três épocas distintas: inverno de $2001\left(\mathrm{~F}_{8: 9}\right.$ e $\left.\mathrm{F}_{24: 25}\right)$ em Ijaci; águas de $2001\left(\mathrm{~F}_{8: 10}\right.$ e $\left.\mathrm{F}_{24: 26}\right)$ e secas de $2002\left(\mathrm{~F}_{8: 11}\right.$ e $\left.\mathrm{F}_{24: 27}\right)$ ambos em Lavras. Utilizou-se o delineamento látice simples 18 x 18 em Ijaci, e triplo nas duas outras épocas. Entre os 105 pares de primers utilizados, 30 foram polimórficos nos genitores e no bulk de DNA das linhagens $\mathrm{F}_{24}$ e utilizados, juntamente com as avaliações experimentais, na análise de regressão linear múltipla - Stepwise. Foram identificados sete QTLs para a produtividade de grãos em $\mathrm{F}_{8}$ e seis QTLs em $\mathrm{F}_{24}$, sendo o marcador derivado do 'ESAL686' (BM156) o que exibiu maior efeito para aumentar a produtividade. Para peso de 100 sementes foram identificados cinco marcadores em $\mathrm{F}_{8}$ e dois em $\mathrm{F}_{24}$, todos provenientes do genitor 'ESAL686' e o que contribuiu com o maior peso foi o X61293. A maioria dos QTLs se expressou em um só ambiente.
\end{abstract}

Termos para indexação: QTLs, marcadores microssatélites, Phaseolus vulgaris.

\begin{abstract}
Aiming to identify QTLs for grain yield and for 100 seed weight of common bean (Phaseolus vulgaris L.), microsatellite markers (SSR) affected by natural selection were selected in a population derived from the cross 'Carioca MG' $\mathrm{x}$ 'ESAL 686', advanced by the bulk breeding until $\mathrm{F}_{24}$. One hundred and seven $\mathrm{F}_{8}$ lines, and $107 \mathrm{~F}_{24}$, were evaluated in three environments: Winter of $2001\left(\mathrm{~F}_{8: 9}\right.$ and $\left.\mathrm{F}_{24: 25}\right)$ at Ijaci county; spring/summer of $2001\left(\mathrm{~F}_{8: 10}\right.$ and $\left.\mathrm{F}_{24: 26}\right)$ and summer/fall of $2002\left(\mathrm{~F}_{8: 11}\right.$ and $\left.\mathrm{F}_{24: 27}\right)$, both at Lavras county. Simple lattice 18 x 18 experimental design was used at Ijaci, and triple lattice in the others environments. Thirty polymorphic pair of primers were selected among 105, through the parents and a bulk of the $\mathrm{F}_{24}$ lines. The molecular and the experimental data were used in the multiple linear regression analysis (stepwise). Seven QTLs for grain yield were identified in $\mathrm{F}_{8}$ and six in $\mathrm{F}_{24}$, and the BM156 marker (derived from 'ESAL 686') showed the major effect. For 100 seed weight five QTLs were identified in $\mathrm{F}_{8}$ and two in $\mathrm{F}_{24}$, all of them derived from 'ESAL 686', and the major effect was exhibited by X61293 marker. Most of the QTLs expressed in only one environment.
\end{abstract}

Index terms: QTLs, microsatellite markers, Phaseolus vulgaris.

(Recebido em 4 de novembro de 2005 e aprovado em 28 de julho de 2006)

\section{INTRODUÇÃO}

A maioria dos caracteres de importância econômica resulta da ação conjunta de vários genes e do ambiente (ALLARD, 1999). Eles são denominados poligênicos ou quantitativos, como a produtividade de grãos em feijão, que exibem baixas herdabilidades nas populações segregantes, porque a maior parte da variação fenotípica não é de natureza genética (RAMALHO et al., 1993). Conseqüentemente, os ganhos obtidos com a seleção são reduzidos.

Com o desenvolvimento dos marcadores moleculares, há perspectivas para uma análise mais detalhada dos caracteres quantitativos, permitindo detectar, mapear e estimar os efeitos de regiões genômicas que os controlam e suas interações com ambientes (EDWARDS et al., 1987). Tais regiões genômicas são referidas como QTLs (Quantative trait loci) e cada uma pode incluir um ou mais poligenes do caráter quantitativo. Assim, as dificuldades da análise fenotípica podem ser reduzidas por meio da identificação direta de QTLs por meio de marcadores moleculares.

$\mathrm{Na}$ maioria dos procedimentos que identificam marcadores ligados a QTLs exige-se que os marcadores

\footnotetext{
${ }^{1}$ Mestre em Genética e Melhoramento de Plantas - Departamento de Biologia/DBI da Universidade Federal de Lavras/UFLA - Cx. P. 3037 - $37200-000$ Lavras, MG - taislenebutarello@hotmail.com

2Doutor em Genética e Melhoramento de Plantas - Professor do Departamento de Biologia/DBI da Universidade Federal de Lavras/UFLA - Cx. P. 3037 37200-000 - Lavras, MG - jbsantos@ufla.br

${ }^{3}$ Doutor em Genética e Melhoramento de Plantas - Professor do Departamento de Biologia/DBI da Universidade Federal de Lavras/UFLA - Cx. P. 3037 37200-000 - Lavras, MG - magnoapr@ufla.br

${ }^{4}$ Doutor em Genética e Melhoramento de Plantas - Instituto Agronômico - Cx. P. 28 - 13001-970 - Campinas, SP - epamorim@iac.sp.go.br

${ }^{5}$ Doutor em Genética e Melhoramento de Plantas - Syngenta - Cx. P. 42 - 38300-000 - Ituiutaba, MG - nara.silva@syngenta.com
} 
tenham herança mendeliana e não sofram efeito de seleção (LANDER \& BOTSTEIN, 1989; MELO et al., 2002; ZENG, 1994). No entanto, têm sido identificados marcadores moleculares influenciados pela seleção natural e sua associação com maior adaptação (ALLARD, 1999). Além disso, a seleção natural tem se mostrado muito eficiente para aumentar a produtividade de grãos (CORTE, 1999; SILVA et al., 2004). Pode-se então inferir na possibilidade de alguns desses marcadores estarem associados a QTLs de interesse.

Assim, o objetivo deste trabalho foi verificar se marcadores microssatélites (SSR), influenciados pela seleção natural, estão associados a genótipos de interesse agronômico para a produtividade de grãos e peso de 100 sementes.

\section{MATERIAL E MÉTODOS}

A partir do cruzamento das linhagens 'Carioca MG' e 'ESAL 686', a população segregante $\mathrm{F}_{2}$ foi conduzida em bulk até a geração $\mathrm{F}_{8}$, de onde foi tomada uma amostra de 107 plantas (SILVA et al., 2004). A população continuou sendo avançada em bulk até $\mathrm{F}_{24}$, onde novamente foi tomada outra amostra de 107 plantas. O genitor 'Carioca MG' é uma cultivar que possui hábito de crescimento indeterminado tipo II, com grãos pequenos, tegumento creme com estrias marrons e de ciclo normal. A `ESAL 686` é uma linhagem com hábito de crescimento determinado tipo I, grãos grandes, tegumento amarelo e de ciclo precoce.

O DNA utilizado foi isolado a partir de $2 \mathrm{~g}$ de folhas jovens de 15 plântulas de cada linhagem, seguindo o protocolo utilizado por Nienhuis et al. (1995). O DNA foi quantificado, utilizando-se o fluorímetro HOFFER TKO100, e então diluído em tampão TE para a concentração de 10 $\mathrm{ng} / \mu \mathrm{L}$ utilizado nas reações. A reação de microssatélite foi realizada em termociclador Mastercycler Gradient 5331 eppendorf versão 2.22 31-09 (RODRIGUES \& SANTOS, 2006). Foram testados 105 pares de primers específicos para o feijoeiro, nos genitores e em um "bulk" constituído por uma mistura eqüitativa de DNA das 107 linhagens $\mathrm{F}_{24: 27}$, para selecionar os marcadores polimórficos, que então foram utilizados para avaliar as 107 linhagens $\mathrm{F}_{24: 27}$ e as 107 $\mathrm{F}_{8: 11}$ (RODRIGUES \& SANTOS, 2006). Cada linhagem foi identificada por 0 , quando apresentou apenas o fragmento de DNA proveniente do genitor 'Carioca MG', por 1 se apresentou ambos os fragmentos e por 2, se o fragmento veio do genitor `ESAL 686`.

As linhagens foram avaliadas também quanto à produtividade de grãos e peso de 100 sementes. A produtividade de grãos foi avaliada por Silva et al. (2004) em três épocas: inverno de $2001\left(\mathrm{~F}_{8: 9}\right.$ e $\left.\mathrm{F}_{24: 25}\right)$, semeadura em agosto, em Ijaci, utilizando o látice simples 18 x 18, parcela de uma linha de um metro espaçada de $0,5 \mathrm{M}$, com densidade de 15 sementes; águas de $2001\left(\mathrm{~F}_{8: 10}\right.$ e $\left.\mathrm{F}_{24: 26}\right)$, semeadura em novembro de 2001 e secas de $2002\left(\mathrm{~F}_{8: 11}\right.$ e $\mathrm{F}_{24: 27}$ ), semeadura em março de 2002, ambos em Lavras, utilizando o látice triplo 18 x 18, parcela de duas linhas de dois metros, espaçadas de 0,5 M, e densidade de 15 sementes por metro. Em todas as épocas foi avaliado o peso de grãos por parcela. O peso de 100 sementes foi avaliado nas mesmas linhagens $\mathrm{F}_{8: 11}$ e $\mathrm{F}_{24: 27}$, utilizando-se o delineamento inteiramente casualizado com duas repetições.

Foi realizada a identificação de QTLs por meio da regressão linear múltipla. $\mathrm{Na}$ análise, os marcadores moleculares corresponderam às variáveis independentes e as avaliações fenotípicas às variáveis dependentes (EDWARDS et al., 1987). Utilizou-se a produtividade de grãos média de cada linhagem, avaliada por ambiente, de $\mathrm{F}_{8: 9}$ a $\mathrm{F}_{8: 11}$ e de $\mathrm{F}_{24: 25}$ a $\mathrm{F}_{24: 27-}$, e também a produtividade média dos três ambientes de cada linhagem $\mathrm{F}_{8}$ e $\mathrm{F}_{24}$. Foram utilizadas também as avaliações de peso de 100 sementes das linhagens $\mathrm{F}_{8}$ e $\mathrm{F}_{24}$.

O processo de seleção de variáveis regressoras foi o Stepwise, segundo Draper \& Smith (1981) e foi aplicado para obter uma estimativa ótima dos valores genotípicos dos QTLs, dos seus erros padrão e da porcentagem da variação fenotípica em cada avaliação experimental. Para identificar qual dos alelos de microssatélites é marcador do QTL de interesse, foi realizada a análise por ponto, semelhante ao procedimento usado por Ferreira (1995).

\section{RESULTADOS E DISCUSSÃO}

Foram utilizados 105 pares de primers SSR, específicos para Phaseolus vulgaris, sendo 37 desenvolvidos por Yu et al. (2000), 68 desenvolvidos por Gaitán-Solís et al. (2002), entre os quais 12 e 18 apresentaram polimorfismo, respectivamente. Todos os 30 locos polimórficos foram afetados pela seleção natural e os alelos

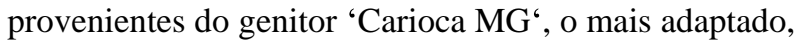
teveram suas freqüências aumentadas em 29 dos 30 locos polimórficos, de $40 \%$ a $100 \%$, com maior intensidade em $\mathrm{F}_{24}$. Em apenas um loco a freqüência foi reduzida em $72 \%$ já na geração $\mathrm{F}_{8}$ e mantida até em $\mathrm{F}_{24}$ (RODRIGUES \& SANTOS, 2006)

A produtividade de grãos é uma das características mais importantes, embora seja a mais complexa, pois é dependente de vários outros caracteres e de inúmeros fatores ambientais. As linhagens analisadas por Silva et al. 
(2004) exibiram diferenças significativas $(\mathrm{P} \leq 0,01)$ em todas as gerações. Na análise conjunta a autora detectou a mesma diversidade genética das linhagens, bem como a interação significativa por ambientes.

No presente estudo, foram identificados dois marcadores ligados a QTLs da produtividade de grãos em $\mathrm{F}_{8}$, na safra de inverno de 2001, destacando-se o BM156, proveniente do genitor 'ESAL686', que contribuiu para aumentar a produtividade em $11,08 \%$ (Tabelas 1 e 2). Na época das águas foram identificados quatro marcadores ligados a QTLs, o BM175 proveniente do 'ESAL686' explicou 6,47\% da variação da produtividade, e os outros três (BM154, BM152 e X61293) contribuíram em conjunto para reduzir a expressão em $14,65 \%$. Para o experimento realizado na safra das secas, foram identificados três marcadores ligados a QTLs, e sobressaíram o JO1263 e o BM175, derivados do 'ESAL 686', explicando 14,11\% da variação fenotípica, no sentido de aumentar a produtividade. A análise conjunta, envolvendo as três épocas, identificou dois marcadores ligados a QTLs derivados do 'ESAL 686', sendo um deles no sentido de aumentar a expressão do caráter (BM156) e o outro de diminuir (BM154), porém com magnitudes similares.

O marcador BM154 já tinha sido identificado no experimento conduzido na safra das águas e das secas e o marcador BM156 também já fora observado na safra de inverno, ambos marcando o alelo do 'ESAL686'. Portanto, eles são mais úteis para auxiliarem na seleção, devido a maior estabilidade. Assim, deve-se selecionar o alelo do genitor 'Carioca MG' ou do 'ESAL 686', dependendo de quem está ligado ao QTL para maior produtividade de grãos.

Na população $\mathrm{F}_{24}$ foram identificados quatro QTLs para a safra de inverno (Tabelas 1 e 2), destacando-se o BM156, com efeito na produção semelhante ao observado em $\mathrm{F}_{8}$, porém com menor intensidade $(6,81 \%)$. Os demais marcadores (BM157, U77935 e BM201) foram responsáveis em reduzir a expressão fenotípica e explicaram $12,22 \%$ da variação (Tabela 1). Na época das águas foram identificados dois marcadores, ambos no sentido de reduzir a produtividade, derivados do 'ESAL686' e contribuindo em conjunto com $15,92 \%$ da variação fenotípica. Na época das secas apenas um marcador ligado a QTL foi identificado (BM210), no sentido de aumentar em 8,75\% a produção e proveniente do 'ESAL686'.

Considerando as médias das três épocas de semeadura, foram identificados quatro marcadores ligados a QTLs que controlam a produção explicando em conjunto $24,56 \%$ da variação fenotípica. Entre eles destacou-se o
BM156, derivado do 'ESAL686' (11,05\%), ficando confirmado o seu efeito e estabilidade já observados em $\mathrm{F}_{8}$ e assim, o seu maior valor para a seleção assistida. O QTL identificado pelo primer BM157, com efeito oposto, também exibiu alguma estabilidade expressando-se nas diferentes gerações sempre no inverno. No geral, os marcadores de QTLs foram de pequeno efeito e instáveis e podem ser utilizados no início do programa de melhoramento, na fase de plantas ou quando não se dispõe de sementes suficientes para avaliação experimental com maior precisão.

As magnitudes e instabilidades dos QTLs detectados estão de acordo com as observações de Melo et al. (2002) e Teixeira (2004), de que é realmente muito difícil identificar um marcador estável para a produtividade de grãos, que sofre grandes influências ambientais. As mudanças nas proporções genotípicas com as gerações, devido ao efeito da seleção natural, tanto as relacionadas à produtividade de grãos, quanto dos marcadores, podem também explicar, pelo menos em parte, a aparente instabilidade dos QTLs em $\mathrm{F}_{8}$ e $\mathrm{F}_{24}$. Especialmente nos casos de redução da freqüência do marcador devido à seleção natural, a amostragem na população segregante fica comprometida e conseqüentemente, o efeito dos QTLs por eles identificados. Além disso, as magnitudes estimadas dos efeitos dos QTLs podem também ficar superestimadas (BERNARDO, 2002).

Outra característica de grande importância no melhoramento é o tamanho da semente, por estar relacionada à aceitação comercial da cultivar. Embora seja um caráter com alta herdabilidade (RAMALHO et al., 1993), a disponibilidade de marcadores pode também auxiliar na seleção, principalmente na condução das populações segregantes pelo método da população, em que a seleção natural exerce grande efeito para reduzir o tamanho da semente (CORTE, 1999).

Para esse caráter a 'Carioca $M G$ ' possui sementes pequenas, com peso de 100 sementes de 18 a 20 g, enquanto a 'ESAL 686' apresenta sementes grandes, superior a $35 \mathrm{~g}$ por 100 sementes.

$\mathrm{Em}_{\mathrm{F}}$ foram identificados cinco marcadores ligados a QTLs, todos derivados da 'ESAL 686' e contribuíram para aumentar o peso da semente. O marcador X61293 foi quem explicou a maior parte da variação fenotípica $(18,65 \%)$ e todos os marcadores em conjunto conseguiram explicar $38,49 \%$, mais de um terço de toda a variação fenotípica, mostrando que podem ser ferramentas importantes no processo de seleção, especialmente nas primeiras gerações. Esse resultado está de acordo com os observados por Melo et al. (2002), Park et al. (2000) e Teixeira (2004). 
TABELA 1 - Resumo das análises de regressão linear múltipla da produtividade de grãos utilizando o processo de Stepwise para a seleção dos marcadores em $\mathrm{F}_{8}$ e $\mathrm{F}_{24}$.

\begin{tabular}{|c|c|c|c|c|}
\hline Marcadores & $\begin{array}{l}\text { Estimativas dos } \\
\text { Parâmetros }\end{array}$ & $\mathbf{R}^{2}$ parcial & Erro padrão & Teste de $\mathbf{F}^{*}$ \\
\hline \multicolumn{5}{|c|}{ Linhagem $\mathrm{F}_{8}-$ Inverno de 2001} \\
\hline Intercepto & $4.401,27$ & & 153,75 & 819,43 \\
\hline BM156 & 331,72 & 0,1108 & 112,88 & 13,08 \\
\hline BM157 & $-382,19$ & 0,0342 & 187,32 & 4,16 \\
\hline \multicolumn{5}{|c|}{ Linhagem $\mathrm{F}_{8}-$ Águas de 2001} \\
\hline Intercepto & $1.452,52$ & & 78,64 & 341,20 \\
\hline BM175 & 194,18 & 0,0647 & 51,88 & 7,26 \\
\hline BM154 & $-108,74$ & 0,0689 & 44,62 & 8,27 \\
\hline BM152 & $-150,35$ & 0,0409 & 69,00 & 5,11 \\
\hline X61293 & $-98,78$ & 0,0367 & 45,37 & 4,74 \\
\hline \multicolumn{5}{|c|}{ Linhagem $F_{8}-$ Seca de 2002} \\
\hline Intercepto & $2.234,43$ & & 78,45 & 811,12 \\
\hline JO1263 & 210,26 & 0,0690 & 65,89 & 7,78 \\
\hline BM175 & 189,39 & 0,0721 & 56,63 & 8,72 \\
\hline BM154 & $-105,44$ & 0,0373 & 48,78 & 4,67 \\
\hline \multicolumn{5}{|c|}{ Linhagem $\mathrm{F}_{8}-$ Conjunta } \\
\hline Intercepto & $2.753,08$ & & 79,49 & $1.199,41$ \\
\hline BM156 & 118,26 & 0,0462 & 51,05 & 5,37 \\
\hline BM154 & $-96,39$ & 0,0577 & 40,37 & 6,43 \\
\hline \multicolumn{5}{|c|}{ Linhagem $\mathrm{F}_{24}-$ Inverno de 2001} \\
\hline Intercepto & $5.116,97$ & & 100,01 & $2.617,94$ \\
\hline BM156 & 332,35 & 0,0681 & 117,96 & 7,67 \\
\hline BM157 & $-490,21$ & 0,0491 & 187,67 & 5,78 \\
\hline U77935 & $-369,21$ & 0,0389 & 143,36 & 4,75 \\
\hline BM201 & $-172,25$ & 0,0342 & 82,98 & 4,31 \\
\hline \multicolumn{5}{|c|}{ Linhagem $\mathrm{F}_{24}-$ Águas de 2001} \\
\hline Intercepto & $1.965,57$ & & 40,55 & $2.349,88$ \\
\hline JO4555 & $-114,57$ & 0,0646 & 40,55 & 7,98 \\
\hline U77935 & $-219,10$ & 0,0946 & 65,95 & 10,96 \\
\hline \multicolumn{5}{|c|}{ Linhagem $\mathrm{F}_{24}-$ Seca de 2002} \\
\hline Intercepto & $2.629,09$ & & 35,44 & $5.501,52$ \\
\hline BM210 & 216,03 & 0,0875 & 68,08 & 10,07 \\
\hline \multicolumn{5}{|c|}{ Linhagem $\mathrm{F}_{24}-$ Conjunta } \\
\hline Intercepto & $3.225,97$ & & 41,27 & $6.110,49$ \\
\hline BM156 & 173,41 & 0,1105 & 48,68 & 13,05 \\
\hline BM201 & $-73,65$ & 0,0382 & 34,24 & 5,00 \\
\hline BM157 & $-164,15$ & 0,0332 & 77,44 & 4,49 \\
\hline U77935 & $-209,36$ & 0,0637 & 59,16 & 8,02 \\
\hline
\end{tabular}

*Significativo a $5 \%$ de probabilidade pelo teste de $\mathrm{F}$. 
TABELA 2 - Médias de cada classe genotípica, por marcador, das linhagens $\mathrm{F}_{8}$ e $\mathrm{F}_{24}$

\begin{tabular}{|c|c|c|c|c|}
\hline \multicolumn{5}{|c|}{ Linhagem $F_{8}$} \\
\hline Primers & Média 'Carioca MG` & Média Heterozigoto & Média `ESAL 686 ' & Época/Caráter \\
\hline BM156 & $4.233,76$ & $4.733,49$ & $5.031,68$ & Inverno/Produção (i) \\
\hline BM157 & $4.770,06$ & $4.150,26$ & $3.744,10$ & Inverno/Produção (i) \\
\hline BM175 & $1.263,07$ & $1.062,04$ & $1.600,95$ & Águas/Produção (a) \\
\hline BM154 & $1.424,39$ & - & $1.215,31$ & Águas/Produção (a) \\
\hline BM152 & $1.405,76$ & $1.052,62$ & $1.219,97$ & Águas/Produção (a) \\
\hline X61293 & $1.427,61$ & 723,76 & $1.251,85$ & Águas/Produção (a) \\
\hline JO1263 & $2.269,98$ & - & $2.655,97$ & Seca/Produção (s) \\
\hline BM175 & $2.275,24$ & $2.032,85$ & $2.632,54$ & Seca/Produção (s) \\
\hline BM154 & $2.409,73$ & - & $2.251,40$ & Seca/Produção (s) \\
\hline BM156 & $2.641,21$ & $2.785,28$ & $2.898,34$ & (i)+(a)+(s)/Produção \\
\hline BM154 & $2.882,30$ & - & $2.674,11$ & (i)+(a)+(s)/Produção \\
\hline X61293 & 24,13 & 26,83 & 27,82 & Secas/Peso de 100 sem. \\
\hline K03289 & 25,20 & 26,91 & 29,14 & Secas/Peso de $100 \mathrm{sem}$. \\
\hline X52626 & 25,62 & - & 28,56 & Secas/Peso de 100 sem. \\
\hline BM152 & 25,57 & 27,55 & 27,79 & Secas/Peso de $100 \mathrm{sem}$. \\
\hline GATS91 & 25,32 & 26,14 & 26,77 & Secas/Peso de $100 \mathrm{sem}$. \\
\hline \multicolumn{5}{|c|}{ Linhagem $\mathrm{F}_{24}$} \\
\hline BM156 & $4.876,89$ & $5.520,79$ & $5.522,00$ & Inverno/Produção (i) \\
\hline BM157 & $5.017,76$ & $4.702,96$ & $3.694,86$ & Inverno/Produção (i) \\
\hline U77935 & $5.021,32$ & $4.331,43$ & $4.497,49$ & Inverno/Produção (i) \\
\hline BM201 & $5.043,59$ & - & $4.739,82$ & Inverno/Produção (i) \\
\hline JO4555 & $1.930,84$ & - & $1.692,60$ & Águas/Produção (a) \\
\hline U77935 & $1.915,83$ & $1.556,28$ & $1.499,87$ & Águas/Produção (a) \\
\hline BM210 & $2.630,42$ & $2.582,42$ & $3.079,92$ & Seca/Produção (s) \\
\hline BM156 & $3.120,34$ & $3.406,33$ & $3.479,45$ & (i)+(a)+(s)/Produção \\
\hline BM201 & $3.196,76$ & - & $3.080,60$ & (i)+(a)+(s)/Produção \\
\hline BM157 & $3.179,30$ & $3.112,24$ & $2.684,67$ & (i)+(a)+(s)/Produção \\
\hline U77935 & $3.201,00$ & $2.852,58$ & $2.854,14$ & (i)+(a)+(s)/Produção \\
\hline BM211 & 22,57 & - & 24,16 & Secas/Peso de 100 sem. \\
\hline GATS91 & 22,37 & 22,52 & 23,79 & Secas/Peso de $100 \mathrm{sem}$. \\
\hline
\end{tabular}

Para as linhagens $\mathrm{F}_{24}$ foram encontrados apenas dois marcadores ligados a QTL para peso de 100 sementes, ambos derivados da 'ESAL 686', aumentando a expressão do caráter e explicando em conjunto $11,76 \%$ da variação fenotípica (Tabela 3). Observou-se apenas um dos marcadores detectados em $\mathrm{F}_{8}$ e a aparente alta instabilidade deveu-se à forte redução de freqüência dos marcadores derivados do 'ESAL 686' ou mesmo a eliminação de alguns pela seleção natural.

Considerando que o tamanho pequeno da semente é indesejável, os QTLs identificados pelos marcadores selecionados foram favoráveis ao melhoramento, para se obter sementes de maior tamanho, especialmente para serem usados quando se utiliza o método da população, em que 
TABELA 3 - Resumos das análises de regressão múltiplas para peso de 100 sementes, utilizando o processo de Stepwise, para seleção dos marcadores em $\mathrm{F}_{8: 11}$ e $\mathrm{F}_{24: 27}$.

\begin{tabular}{|c|c|c|c|c|}
\hline Marcadores & $\begin{array}{c}\text { Estimativas dos } \\
\text { Parâmetros }\end{array}$ & $\mathbf{R}^{2}$ parcial & Erro padrão & Teste $\mathbf{F}^{*}$ \\
\hline \multicolumn{5}{|c|}{ Família $\mathrm{F}_{8: 11}$} \\
\hline Intercepto & 21,72 & & 0,72 & 911,56 \\
\hline X61293 & 1,71 & 0,1865 & 0,35 & 24,08 \\
\hline K03289 & 1,39 & 0,0472 & 0,46 & 7,09 \\
\hline X52626 & 1,29 & 0,0801 & 0,45 & 11,36 \\
\hline BM152 & 1,10 & 0,0258 & 0,53 & 4,24 \\
\hline GATS91 & 0,91 & 0,0453 & 0,39 & 7,21 \\
\hline \multicolumn{5}{|c|}{ Família $\mathrm{F}_{24: 27}$} \\
\hline Intercepto & 22,23 & & 0,23 & $9.078,08$ \\
\hline BM211 & 0,66 & 0,0377 & 0,31 & 4,44 \\
\hline GATS91 & 0,60 & 0,0799 & 0,22 & 9,12 \\
\hline
\end{tabular}

a seleção natural atua no sentido de reduzir o peso da semente.

É importante considerar que existe a possibilidade dos marcadores que identificam QTLs, serem independentes das regiões genômicas identificadas. Nesse caso, eles podem ter detectado os QTLs simplesmente pelo efeito da seleção natural, reduzindo a freqüência, simultaneamente, do QTL e do marcador e gerando associações em consequiência de uma amostragem inadequada da população segregante.

\section{CONCLUSÕES}

Existem marcadores influenciados pela seleção natural explicando o efeito de QTLs, tanto da produção quanto do peso de 100 sementes. A expressão dos QTLs foi no geral instável e pode ter sido incrementada pela seleção natural.

\section{REFERÊNCIAS BIBLIOGRÁFICAS}

ALLARD, R. W. Principles of plant breeding. 2. ed. New York: J. Wiley \& Sons, 1999. 254 p.

BERNARDO, R. Breeding for quantitative traits in plants. Woodbury: Stemma, 2002. 369 p.

CORTE, H. R. Comportamento de populações segregantes de feijão, avançadas pelo método do "bulk", por dezessete gerações. 1999. 95 p. Dissertação (Mestrado em Genética e Melhoramento de Plantas) - Universidade Federal de Lavras, Lavras, 1999.
DRAPER, N. R.; SMITH, H. Applied regression analysis. 2. ed. New York: J. Wiley \& Sons, 1981. 709 p.

EDWARDS, M. D.; STUBER, C. W.; WENDEL, J. F. Molecular-marker-facilitated investigations of quantitative trait loci in maize. Numbers, genomic distribution and types of gene action. Genetics, Bethesda, v. 116, p. 113-125, 1987.

FERREIRA, D. F. Eficiência de métodos de mapeamento de locos quantitativos (QTLs) e da seleção assistida por marcadores moleculares através de simulação. 1995. 210 p. Tese (Doutorado em Genética e Melhoramento de Plantas) - Escola Superior de Agricultura Luiz de Queiroz, Piracicaba, 1995.

GAITÁN-SOLÍS, E.; DUQUE, M. C.; EDWARDS, K. J.; TOHME, J. Microsatellite repeats in common bean (Phaseolus vulgaris): isolation, characterization, and cross-species amplification in Phaseolus ssp. Crop Science, Madison, v. 42, p. 2128-2136, 2002.

LANDER, E. S.; BOTSTEIN, D. Mapping mendelian factors underlying quantitative trait using RFLP linkage maps. Genetics, Bethesda, v. 121, p. 185-199, 1989.

MELO, L. C.; SANTOS, J. B.; FERREIRA, D. F. Mapping and stability of QTLs for seed weight in common beans under different environments. Crop Breeding and Applied Biotechnology, Londrina, v. 2, n. 2, p. 227-236, 2002. 
NIENHUIS, J.; TIVANG, L.; SCKROCH, P.; SANTOS, J. B. Genetic relationships among cultivars and lines of lima bean (Phaseolus lunatus L.) as measure by RAPD markers. Journal of the American Society for Horticutural Science, Alexandria, v. 120, n. 2, p. 300-306, 1995.

PARK, S. O.; COYNE, D. P.; JUNG, G.; SKROCH, P. W.; ARNAUD-SANTANA, E. SETADMEN, J. R.; ARIYARATHNE, H. M.; NIENHUIS, J. Mapping of QTL for seed size and shape traits in common bean. Journal American Society of Horticultural Science, Alexandria, v. 125 , n. 2, p. 466-475, 2000.

RAMALHO, M. A. P.; SANTOS, J. B. dos; ZIMMERMANN, M. J. de O. Genética quantitativa em plantas autógamas: aplicações ao melhoramento do feijoeiro. Goiânia: UFG, 1993. 271 p.

RODRIGUES, T. B.; SANTOS, J. B. dos. Effect of natural selection on common bean microsatellite (SSR) alleles.
Genetic and Molecular Biology, Ribeirão Preto, v. 29, n. 2, p. 345-352, 2006.

SILVA, N. O.; RAMALHO, M. A. P.; ABREU, A. B. F.; CARNEIRO, J. E. de S. Performance of common bean families after different generations under natural selection. Genetics and Molecular Biology, Ribeirão Preto, v. 27, n. 4, p. 574-578, 2004.

TEIXEIRA, F. F. Mapeamento de QTLs para caracteres do feijoeiro por meio de microssatélites. 2004. 189 p. Tese (Doutorado em Genética e Melhoramento de Plantas) Universidade Federal de Lavras, Lavras, 2004.

YU, K.; PARK, S. J.; POYSA, V.; GEPTS, P. Integration of simple sequence repeat (SSR) markers into a molecular linkage map of common bean (Phaseolus vulagaris L.). Journal Hered, [S.1.], v. 91, n. 6, p. 429-434, 2000.

ZENG, Z. B. Precision mapping of quantitative trait loci. Genetics, Bethesda, v. 136, p. 1457-1468, 1994. 